\title{
Rural-Urban Difference in Natural Menopausal Age and the Correlating Factors
}

\author{
Saw Ohn $\operatorname{Mar}^{*}{ }^{\mathbb{D}}$, Resni Mona $^{1}$
}

\begin{abstract}
Objectives: Early menopause is shown to correlate with an increased rate of cardiovascular diseases with age advancement. Smoking, physical activity, body mass index (BMI), and the socio-economic level are consistently linked with the onset of menopause though there is no consensus on the residential factor. Considering the undesirable relation of menopause with women's health, the present review sought to identify the correlation between the rural-urban factor and natural menopausal age.

Methods: A comprehensive literature search, covering publications from 1984 to 2017, was done using several databases such as MEDLINE, PubMed, and Google scholar. Evidence from 13 research articles was analyzed for a rural-urban difference in natural menopausal age. The search was later expanded to explore correctable confounding factors such as smoking habits, physical activities, and BMI.

Results: Rural women in the Asian region appeared to reach their natural menopausal age earlier than their urban counterparts. This was in contrast with the majority of findings in the non-Asian regions, suggesting a regional variation in the rural-urban difference in natural menopausal age. Based on the findings, earlier menopausal age was related to smoking prevalence and this relationship was consistent in both Asian and non-Asian regions. Similarly, higher physical activity was linked to the early age of natural menopause in both Asian and non-Asian regions. Finally, the results revealed the association between higher BMI and higher menopausal age in the Asian region although this association was not observed in the non-Asian regions.

Conclusions: The rural-urban difference in menopausal age has regional variations with rural Asian women reaching menopause earlier than their urban counterparts, but this association was not replicated in the non-Asian regions. Eventually, this difference was affected by factors such as tobacco smoking, high physical activity, and BMI.

Keywords: Rural, Urban, Natural menopause, Age, Smoking, Physical activity, BMI
\end{abstract}

\section{Introduction}

The onset of menopause often signals an unwelcome transition in the lives of many women. According to Palacios et al (1), although the timing of natural or spontaneous menopause may vary genetically, ethnically, and geographically, the latter variations are found in the natural menopausal age of major regions in the world including Europe (50.1-52.8 years), North America (50.551.4), Latin America (43.8-53), and Asia (42.1-49.5).

The age of the onset of menopause is suggested to significantly affect women's health. This is corroborated by the UK Biobank data which represented that earlier menopausal age ( $<47$ years) is independently correlated with the higher incidence of cardiovascular diseases (CVDs) in later life (2). Additionally, a significant association exists between lower menopausal age, longer duration of postmenopausal period, and a shorter period between menarche and menopause, with the risk of CVD or CVD-related mortality (3-5).

Early menopause may occur due to medical interventions or genetic diseases although some social determinants are significantly related to the onset of natural menopause. These social determinants include education (6-8), oral contraceptive use (6-8), employment (6), smoking (6-8), body weight (6-8), alcohol consumption $(6,8)$, self-rated health (6), physical activity (6-8), younger generation (7), early menarche $(7,8)$, age at first birth $(7)$, parity $(7,8)$, an experience of severe food shortage (7), socioeconomic status $(8)$, and diet $(7,8)$. What is missing from the list is the residential factor, especially the rural-urban factor, even though numerous direct and indirect studies have focused on the rural-urban difference in the onset of natural menopause.

Given the undesirable relation of menopause with women's health, this review aimed to establish a correlation between the rural-urban factor and natural menopausal age. Such findings will be useful in the formation and implementation of health policies that respond to the needs of rural and urban women.

\section{Methods}

A comprehensive literature search was done electronically for scientific publications written in English or bilingual (English with one other language) by using databases such as MEDLINE, PubMed, and Google Scholar. The key search terms were "menopause", "age", "urban", and 
"rural" as the scope of the review was to determine the association between rural and urban residences with the age of the natural onset of menopause. In addition, the search covered academic publications from 1984 to 2017. Once the association between rural-urban and the age of natural menopause was established, the literature search was expanded to explore the literature for some correctable confounding factors by focusing on smoking habit, physical activities, and the body mass index (BMI) between rural and urban populations with stratification of the countries where the studies on the age for the onset of natural menopause originated.

\section{Results}

Our literature search uncovered 13 research articles that shed light on rural-urban differences in natural menopausal age, including 6 from India, 3 from Iran, 2 from Europe, as well as and 1 from China, Mexico, and South Africa, respectively (Table 1).

Regional Variation in Rural-Urban Differences in Menopausal Age

Of all the 13 studies on menopausal age, nine were from the Asian region including India $(n=6)$, Iran (2), and China (1) while only 2 studies were found from Europe including Spain (1) and Poland (1), respectively. Both Africa and North America contributed one publication each.

Nine of the studies indicated that the rural population begins their natural menopause earlier than their urban counterparts $(10,11,14,16-21)$ with statistically significant differences in about half of these findings (10,19-21). The other four studies, however, reported contradictory findings $(9,12,13,15)$ with one showing a significant level of difference (15). Of the nine studies that suggested an association between rural residency and earlier menopause, eight were from Asia. This association is in contrast with the majority of findings in the non-Asian regions except for Mexico (10). In these regions, the rural population appeared to experience later onset of natural menopause compared to their urban or semi-urban counterparts. Therefore, it is apparent that rural-urban differences in the age for the onset of natural menopause have regional variations.

\section{Discussion}

The difference in the age for the onset of natural menopause between the rural and urban population is apparent in all studies included in our review, with statistically significant findings in some of the studies. Furthermore, our review of the literature showed that women living in rural areas of Asia are more likely to begin their menopause earlier than their urban counterparts. Therefore, it is believed that it is justifiable to suggest that "rural" and "urban" factors may play a central role in early- or late-onset menopause age. However, it must be noted that "rural" or "urban" residence is not clearly defined in any of the analyzed studies. Indeed, the term "rural" or "urban" can be a multidimensional classification that can take into account economic activities, geographical dimensions, and population density (22).

Although the reasons for the rural-urban variation in menopausal age have not been clearly identified in the reviewed literature, some studies have addressed this issue. Based on the report of a study in Mexico, the genetic factor was considered as the main determinant (10) although another study indicated that the cause is multifactorial, including BMI, age, and environmental context (13). Taking into account the significant association between rural residency and low BMI with earlier menopausal age, the findings of a study in Iran demonstrated that ruralurban socioeconomic differences are the responsible factor in this regard (21). This conclusion was mirrored by the UN data on rural women which indicated that women living in rural areas are faced with numerous constraints including access to affordable, adequate, and holistic health services that address physical, mental, and emotional well-being (23).

Overall, the urban population has better general health outcomes, even those who may live within the same poverty line as those in the rural area. The possible reason for this "urban health advantage" is the proximity of wealth and poverty within cities which bring benefits to those less well-off. More importantly, the urbanites also enjoy higher levels of social support and greater social cohesion, more access to the necessities of life, more health-friendly environment, along with more politically and socially mobilized health resources (24). For example, life expectancy at birth is substantially lower for both American males and females in rural areas compared to the urban areas. This disparity was associated with mortality and/or morbidity from both communicable and non-communicable diseases, as well as physical or mental illnesses conditions greatly influenced by access to quality health care (25). However, rural-urban health disparities cannot be solely observed due to the effect of rurality. It may be the result of a combination of multiple factors that are deficient among the rural population, including socioeconomic status, service availability, personal risk levels, environmental and occupational conditions, transportation conditions, and ethnicity (26).

It was further speculated that there may be other underlying factors that correlate with the rural-urban difference in the natural menopausal age since it may have regional variations, especially between Asian and nonAsian regions.

Possible Correlates of Rural-Urban Differences in Natural Menopausal Age

\section{Smoking Habit}

The prevalence of tobacco smoking among rural and urban women in Asian and non-Asian populations can 
Table 1. Summary of Articles on Age for the Onset of Natural Menopause Among Rural and Urban Women

\begin{tabular}{|c|c|c|c|c|c|c|c|}
\hline $\begin{array}{l}\text { First Author/ } \\
\text { Year }\end{array}$ & Country & Study Design & $\begin{array}{l}\text { Sample Size } \\
\text { Rural/Urban }\end{array}$ & Comparison & Rural & Urban & $\begin{array}{l}\text { Significance } \\
\text { Level }\end{array}$ \\
\hline Walker (9) & $\begin{array}{l}\text { South } \\
\text { Africa }\end{array}$ & Cross-sectional & $1850 / 1255$ & Mean & $49.5 \pm 4.7$ & $48.9 \pm 4.2$ & Not stated \\
\hline Malacara (10) & Mexico & Cross-sectional & 7632 & $\begin{array}{l}\text { Mean (3 } \\
\text { areas) } \\
\text { logistic } \\
\text { regression }\end{array}$ & $\begin{array}{l}47.3 \\
49.0 \\
47.0\end{array}$ & $\begin{array}{l}48.3 \\
48.0 \\
48.3\end{array}$ & $P<0.001^{\#}$ \\
\hline Mohammad (11) & Iran & $\begin{array}{l}\text { Cumulative } \\
\text { distribution (NHS) }\end{array}$ & 8194 & Median & 49.2 & 49.9 & 95\% Cl: 1.00066 \\
\hline Kaczmarek (12) & $\begin{array}{l}\text { Poland } \\
\text { cohorts }\end{array}$ & $\begin{array}{l}\text { 1. } 1948 \text { survey } \\
\text { 2. } 1967 \text { survey } \\
\text { 3. Cross sectional } \\
(2000-2004)\end{array}$ & 7183 & $\begin{array}{l}\text { 1. Mean } \\
\text { 2. Mean } \\
\text { 3. HR }\end{array}$ & $\begin{array}{l}49.28 \\
50.49 \\
\text { Living environ }\end{array}$ & $\begin{array}{l}49.94 \\
50.21 \\
\text { nt }\end{array}$ & $\begin{array}{l}0.93(0.87-1.01) \\
P<0.52\end{array}$ \\
\hline Cristina (13) & Spain & $\begin{array}{l}\text { Pooled data from } 2 \\
\text { research projects }\end{array}$ & $\begin{array}{l}103 \text { rural } \\
744 \text { semi-urban } \\
295 \text { urban }\end{array}$ & Median & $\begin{array}{l}52.07 \text { (rural) } \\
51.9 \text { (semi-ur } \\
51.23 \text { (urban) }\end{array}$ & & \\
\hline Kaur (14) & India & Cross sectional & & $\begin{array}{l}\text { Mean } \\
\text { Median }\end{array}$ & $\begin{array}{l}48.22 \\
(2.47) \\
48.98 \\
(1.12)\end{array}$ & $\begin{array}{l}49.30 \\
(2.80) \\
50.12 \\
(1.15)\end{array}$ & Not stated \\
\hline Dasgupta (15) & India & $\begin{array}{l}\text { Observational cross- } \\
\text { sectional }\end{array}$ & $110 / 70$ & Mean & $\begin{array}{l}46.94 \\
(4.64)\end{array}$ & $\begin{array}{l}44.92 \\
(3.93)\end{array}$ & $\begin{array}{l}P<0.001^{\#} \\
\text { Multivariate } \\
\text { analysis } 7.1 \% \\
\text { variance }\end{array}$ \\
\hline Sagdeo (16) & India & $\begin{array}{l}\text { Observational cross- } \\
\text { sectional }\end{array}$ & $250 / 250$ & Mean & $48.56(2.27)$ & $\begin{array}{l}49.56 \\
(4.12)\end{array}$ & $P<0.0667$ \\
\hline Lewington (17) & China & $\begin{array}{l}\text { Baseline data of } \\
\text { CKB blood based } \\
\text { prospective cohort }\end{array}$ & 300,000 & Mean & $48.0(4.4)$ & $\begin{array}{l}48.5 \\
(4.4)\end{array}$ & Not stated \\
\hline Nidhi Sagar (18) & India & Comparative study & $50 / 50$ & Mean & 48.28 & 49.78 & Not stated \\
\hline Murugan (19) & India & $\begin{array}{l}\text { Cross-sectional door } \\
\text { to door survey }\end{array}$ & & $\begin{array}{l}\text { Early }<45 \text { y } \\
\text { Normal } \\
45-55 \text { y } \\
\text { Late }>55 \text { y }\end{array}$ & $\begin{array}{l}32.69 \% \\
65.11 \% \\
2.2 \%\end{array}$ & $\begin{array}{l}15.86 \% \\
82.77 \% \\
1.37 \%\end{array}$ & $P<0.01^{\#}$ \\
\hline Potsangbam (20) & India & Cross-sectional & 100 & $\begin{array}{l}<48 y \\
\geq 48 y\end{array}$ & $\begin{array}{l}84.8 \% \\
15.2 \%\end{array}$ & $\begin{array}{l}51.9 \% \\
48.1 \%\end{array}$ & $P<0.001^{\#}$ \\
\hline $\begin{array}{l}\text { Parsaeian } \\
(21)\end{array}$ & Iran & $\begin{array}{l}\text { Population based } \\
\text { survey }\end{array}$ & 4898 & Median & 50.3 & 50.7 & $\begin{array}{l}\text { Adjusted HR } \\
1.09(1.01-1.18) \\
P<0.01^{\#} \\
\text { Adjusted OR } \\
1.35(1.12-1.62) \\
P<0.01^{\#}\end{array}$ \\
\hline
\end{tabular}

Note. NHS: National Health Service; Cl: Confidence interval; HR: Hazard ratio; CKB: China Kadoorie Biobank; OR: Odds ratio.

"Statistically significant.

be the contributing factor to the difference in the age for the onset of menopause. Several studies support the notion that the earlier onset of age at natural menopause experienced by the rural population in the Asian region is correlated with tobacco smoking. For example, the prevalence of smoking among rural Indian women population was more than five times that of their urban counterparts (27). However, 2010 data from China appeared to contradict the situation in India, where smoking was equally prevalent among rural and urban women born in the 1930s, and significantly higher among the urban women born in the 1940s onward. Further, smoking prevalence among males living in the rural area was significantly higher than their urban counterparts with a more remarkable difference among the older generation (28). Therefore, it can be assumed that rural Chinese women of the older generation have significantly higher exposure to second-hand tobacco smoke compared to their urban counterparts. Furthermore, Esmaeilzadeh et al (29) reported a higher rate of smoking among women living in the rural than the urban setting in Iran (6.9\% vs. $15.1 \%, P<0.001)$. 
Contrary to the Asian countries, four European countries (i.e., Finland, Germany, Italy, and Spain) were found to have more current smokers among the urban population compared to the rural population with an age-standardized odds ratio at $1.56(95 \% \mathrm{CI}=1.48-1.66)$, as well as the age and education standardized odds ratio at 1.47 (95\% CI=1.38-1.55) for Spain (30). In contrast, a Polish study (31) of three birth cohorts (those born before 1940, between 1940 and 1960, and 1961-1979) demonstrated that rural residency is associated with a nearly two-fold increase in smoking. This may well reflect the finding that, similar to the Asian countries, the mean menopausal age for Polish women is lower among rural residents in the early cohort (1948) although the later cohorts revealed the opposite (1967) or no significant difference (200-2004).

The connection between smoking and the early onset of age at natural menopause was also observed in the African region. In South Africa, earlier menopausal age among urban women was correlated with the findings that the south African urban youths were more likely to smoke $(\mathrm{OR}=1.39,95 \% \mathrm{CI}=1.09-1.75)$ compared to their rural counterpart $(14,32)$. No literature was uncovered to correlate smoking with the onset of age at natural menopause in Mexico.

In summary, the onset of menopause is earlier in either rural or urban settings, where smoking is more prevalent. Therefore, smoking may be one of the correlates of the difference in natural menopausal age between the rural and urban populations.

\section{Physical Activity}

High physical activity may be associated with a lower age for the onset of natural menopause. In the Asian region, a significantly higher proportion of women living in the rural settings engaged in high physical activity compared to their urban counterpart, with the odds ratio of 3.61 for rural $(95 \% \mathrm{CI}=2.36-5.54)$ in India (33), $71.4 \%$ rural vs. $17.7 \%$ urban $(P<0.01)$ in China $(34)$, and $71.2 \%$ rural vs. $44.7 \%(P<0.0001)$ in Iran $(29)$. These appear to be associated with lower natural menopausal age among rural women compared to their urban counterparts in India, China, and Iran (Table 1).

In contrast with the Asian studies, lower menopausal age in the urban area compared to the rural area of South Africa is not compatible with the findings by Peer et al that indicate lower physical activity among the urban population compared to their rural counterpart (OR: 1.45, 95\% CI: 1.12-1.89) (32) Similar observation was made for Spain as less physical activity seems to correlate with lower natural menopausal age. Compared to their rural and urban counterparts, the semi-rural women in Spain who were reported to be engaged in higher physical activity registered the highest age at natural menopause. 35 However, corroborating the Asian studies, a higher age at natural menopause among those living in the rural areas of Poland appears to be associated with significantly less leisure-time inactivity (36).

In general, there is a strong indication of physical activity contributing to the difference observed in the onset of age at natural menopause between urban and rural populations.

\section{Basal Mass Index}

In India, China, and Iran, higher menopausal age among the urban women compared to their rural counterparts appeared to correlate with a higher BMI. A marked difference in BMI was reported between the urban and rural female population in India where the rate of overweight and obesity among the urban women was $47.6 \%$ and $16.4 \%$, respectively, while that of the rural women was $11.3 \%$ and $2.2 \%$, respectively (37). In addition, Jayamani et al (33) reported the odds ratio of urban overweight/obese among the women population as $5.555(95 \% \mathrm{CI}=3.333-10)$. Similarly, a study from Iran (39) reported an adjusted obesity odds ratio at 1.54 (95\% $\mathrm{CI}=1.31-1.80)$ for urban adults where the odds ratio for females was 1.47 (95\% CI =1.26-1.72) (38). However, two contradictory observations were made in China. Using a stratified cluster sampling method, an earlier study showed that the prevalence of obesity is higher in urban areas. More precisely, $10.2 \%, 6.8 \%$, and $6.5 \%$ were reported among women living in the city, township, and rural areas, respectively $(P<0.005)(39)$. This contradicts by a later report based on the data extracted from nationwide breast cancer screening of China which revealed a significantly higher prevalence of overweight/obesity among the rural Chinese women compared to the urban Chinese women $(P<0.001)(40)$.

Marked differences in BMI between rural and urban dwellers were not observed in the non-Asian countries. A study from Mexico found that living in the urban area $(\mathrm{OR}=5.90, P<0.007)$ is independently associated with obesity in older adult individuals (41). Similarly, the rate of overweight/obesity was independent of the dwelling area although higher waist circumference (more than 88 $\mathrm{cm}$ ) was more prevalent among rural dwellers compared to their urban counterpart $(P<0.05)(42)$. Furthermore, the findings of a study of the populations in 10 European countries, including Spain, demonstrated no difference in the prevalence of overweight and obesity between rural and urban areas. Moreover, the analysis of compounding factors such as gender, age, education, or income levels did not reveal additional rural-urban variations (43). Later, it was reported that in 20 European countries, including Poland, overweight and obesity rates are significantly higher among those who live in rural areas compared to those of the urban areas (44).

In summary, although the correlation between BMI and the menopausal age cannot be rationalized in non- 
Asian countries, there is a clear indication of a connection between higher BMI and higher menopausal age in Asian countries, suggesting BMI as one of the contributing factors for earlier menopause among the rural women (Table 1).

Long-term Health Risks of Early Menopause

The menopausal age can be considered as an important factor in stratified risk assessment for CVDs for women. The risk of CVD in women was suggested to increase by a decrease in menopausal age. The comparison among women who reached menopause at age 50-51 years revealed that the risk of CVD was $55 \%, 30 \%$, and $12 \%$ higher among women who reached menopause at age less than 40, 40-44, and 45-49 years old, respectively. In addition, these risks were reported to intensify before 60 years of age (45).

Furthermore, women with early menopause (less than 47 years old) are 1.8, 1.7, and 1.6 times more likely to have osteoporosis at 77 years of age, fragility fracture, and risk of mortality, respectively, when compared to those who experienced late menopause (47 years old or older) (46). Additionally, recently published data from a large prospective cohort study highlighted that the mean natural menopausal age ( $<47.4$ years) was significantly linked to a $19 \%$ increase in the risk of dementia (47).

\section{Limitations}

A meta-analysis of the results compiled from the reviewed studies was not done due to the following reasons:

1. There were some disparities with regard to the method used among the studies. Seven studies used an observational cross-sectional study design $(9,10,14-16,19,20)$ and only one study used the comparative study design but the sample size was rather small (18).

2. The sampling frame was different among the studies. Some data were taken from active collections, either from the community or hospital settings while some were extracted from other sources such as previous menopause-related research projects or the biobank. The pooled data yielding good sample size were extracted from retrospective or prospective research projects that were not related to menopause (11$13,17,21)$. Only seven studies had a considerably large sample size $(9-13,17,21)$.

3. The selection method was not stated in some articles although most of the studies used the convenient sampling technique. In addition, the women were enrolled from randomly selected residential areas only in a study in Poland (12).

4. There were variations in the age inclusion criteria among the studies. The age range varied between 10 and 44 years old with the lowest age at 29 (19) and the highest age at 70 (14). One report had no record of the highest participant's age in its data analysis (17).
5. The inclusion criteria related to the type of menopause was inconsistent among the studies. Surgical menopause was included in some studies $(16-18,21)$ as the purpose of their study was not just to determine the menopausal age among the residents.

6. The women who had natural menopause at an older age were excluded in some studies. In these studies, premenopausal women who reached their menopause at an older age $(>55)$ were excluded in the cross-sectional sampling $(13,18)$.

7. The menopausal age, mean $(9,15-18)$, median $(11,12)$, both mean and median (14), the hazard ratio (12), or the logistic regression of the means (10) were used for comparison. In two Indian studies, the Chi-square test was used to analyze the correlation between menopausal age groups and their place of residence $(14,15)$.

\section{Conclusions and Recommendations}

Our analysis of the available data strongly suggested that rural-urban differences in menopausal age have regional variations. Asian women living in rural areas were more likely to reach menopause earlier than their urban counterpart and this association was not replicated in the non-Asian region. However, rurality by itself may not be the sole predisposing factor for early menopause. Smoking, high physical activity, and low BMI are three variables that may have a significant correlation in this regard. The socioeconomic disparity, as another possible factor, was not determined in this study.

It is well proven that natural estrogen provides both cardio-protective and bone protective effects. Therefore, all women should benefit from the endogenous estrogen by a natural delay in the menopausal age for reducing the risk of osteoporotic fractures, as well as cardiovascular morbidity and mortality. To make this possible, the improvement of social, economic, and environmental conditions of a given community should focus on reinforcing programs and improving physical facilities to allow women better access to a healthier lifestyle including more physical activities, zero smoking, and healthy BMI. Further research should address the health benefit of a delay in natural menopause. It would also be interesting to have an on-going study that evaluates the effect of engaging in regular exercise, maintaining/achieving a healthy weight, or reducing weight in obese/overweight women and smoking cessation on the onset of menopause.

\section{Conflict of Interests}

Authors declare that they have no conflict of interests.

\section{Ethical Issues}

Not applicable.

\section{Financial Support}

We do not receive any funding for this project. 


\section{References}

1. Palacios S, Henderson VW, Siseles N, Tan D, Villaseca P. Age of menopause and impact of climacteric symptoms by geographical region. Climacteric. 2010;13(5):419-428. doi:1 0.3109/13697137.2010.507886

2. Peters SA, Woodward M. Women's reproductive factors and incident cardiovascular disease in the UK Biobank. Heart. 2018;104(13):1069-1075. doi:10.1136/ heartjnl-2017-312289

3. Yang L, Lin L, Kartsonaki C, et al. Menopause characteristics, total reproductive years, and risk of cardiovascular disease among Chinese women. Circ Cardiovasc Qual Outcomes. 2017;10(11). doi:10.1161/circoutcomes.117.004235

4. Ley SH, Li Y, Tobias DK, et al. Duration of reproductive life span, age at menarche, and age at menopause are associated with risk of cardiovascular disease in women. J Am Heart Assoc. 2017;6(11). doi:10.1161/jaha.117.006713

5. Muka T, Oliver-Williams C, Kunutsor S, et al. Association of age at onset of menopause and time since onset of menopause with cardiovascular outcomes, intermediate vascular traits, and all-cause mortality: a systematic review and meta-analysis. JAMA Cardiol. 2016;1(7):767-776. doi:10.1001/jamacardio.2016.2415

6. Gold EB, Crawford SL, Avis NE, et al. Factors related to age at natural menopause: longitudinal analyses from SWAN. Am J Epidemiol. 2013;178(1):70-83. doi:10.1093/aje/ kws421

7. Wang M, Gong WW, Hu RY, et al. Age at natural menopause and associated factors in adult women: findings from the China Kadoorie Biobank study in Zhejiang rural area. PLoS One. 2018;13(4):e0195658. doi:10.1371/journal. pone.0195658

8. Ceylan B, Özerdoğan N. Factors affecting age of onset of menopause and determination of quality of life in menopause. Turk J Obstet Gynecol. 2015;12(1):43-49. doi:10.4274/tjod.79836

9. Walker AR, Walker BF, Ncongwane J, Tshabalala EN. Age of menopause in black women in South Africa. $\mathrm{Br}$ J Obstet Gynaecol. 1984;91(8):797-801. doi:10.1111/j.1471-0528.1984.tb04853.x

10. Malacara JM, Canto de Cetina T, Bassol S, et al. Symptoms at pre- and postmenopause in rural and urban women from three States of Mexico. Maturitas. 2002;43(1):11-19. doi:10.1016/s0378-5122(02)00077-4

11. Mohammad K, Sadat Hashemi SM, Farahani FK. Age at natural menopause in Iran. Maturitas. 2004;49(4):321-326. doi:10.1016/j.maturitas.2004.02.006

12. Kaczmarek M. The timing of natural menopause in Poland and associated factors. Maturitas. 2007;57(2):139-153. doi:10.1016/j.maturitas.2006.12.001

13. Bernis C, Reher DS. Environmental contexts of menopause in Spain: comparative results from recent research. Menopause. 2007;14(4):777-787. doi:10.1097/ gme.0b013e31803020ff

14. Kaur M, Talwar I. Age at natural menopause among rural and urban Punjabi Brahmin females. The Anthropologist. 2009;11(4):255-258. doi:10.1080/09720073.2009.11891112

15. Dasgupta D, Ray S. Menopausal problems among rural and urban women from eastern India. J Soc Behav Health Sci. 2009;3(1):20-33. doi:10.5590/jsbhs.2009.03.1.02
16. Sagdeo M, Arora D. Menopausal symptoms: a comparative study in rural and urban women. Jk Science. 2011;13(1):2326.

17. Lewington S, Li L, Murugasen S, et al. Temporal trends of main reproductive characteristics in ten urban and rural regions of China: the China Kadoorie biobank study of 300000 women. Int J Epidemiol. 2014;43(4):1252-1262. doi:10.1093/ije/dyu035

18. Nidhi Sagar S, Kaur J. Study on menopausal symptoms among women residing in urban and rural areas. Int J Dev Res. 2015;5(11):5987-5992.

19. Murugan A, Vanaja V. Evaluation of some risk factors on the age at menopause in south Indian women. Int J Res Rev Pharm Appl Sci. 2015;5(1):1117-1124.

20. Potsangbam R, Laishram DS, Usham R, Bishwalata RK. Age at Menopause and its Determinants. Ann Int Med Dent Res. 2016;2(6):10-13. doi:10.21276/aimdr.2016.2.6.PH3

21. Parsaeian M, Pouraram H, Djazayery A, et al. An Explanation for Variation in Age at Menopause in Developing Countries Based on the Second National Integrated Micronutrient Survey in Iran. Arch Iran Med. 2017;20(6):361-367.

22. Pizzoli E, Gong X. How to Best Classify Rural and Urban. http://www.stats.gov.cn/english/icas/papers/ p020071114325747190208.pdf. Published January 2007

23. The UN System: Working Together to Empower Rural Women. Overview health. https://www.un.org/ womenwatch/feature/ruralwomen/facts-figures.html. Accessed 26 September 2018.

24. Vlahov D, Galea S, Freudenberg N. The urban health "advantage". J Urban Health. 2005;82(1):1-4. doi:10.1093/ jurban/jti001

25. Singh GK, Daus GP, Allender M, et al. Social determinants of health in the United States: addressing major health inequality trends for the nation, 1935-2016. Int J MCH AIDS. 2017;6(2):139-164. doi:10.21106/ijma.236

26. Smith KB, Humphreys JS, Wilson MG. Addressing the health disadvantage of rural populations: how does epidemiological evidence inform rural health policies and research? Aust J Rural Health. 2008;16(2):56-66. doi:10.1111/j.1440-1584.2008.00953.x

27. Jindal SK, Aggarwal AN, Chaudhry K, et al. Tobacco smoking in India: prevalence, quit-rates and respiratory morbidity. Indian J Chest Dis Allied Sci. 2006;48(1):37-42.

28. Liu S, Zhang M, Yang L, et al. Prevalence and patterns of tobacco smoking among Chinese adult men and women: findings of the 2010 national smoking survey. J Epidemiol Community Health. 2017;71(2):154-161. doi:10.1136/jech2016-207805

29. Esmaeilzadeh S, Delavar MA, Delavar MH. Assess quality of life among Iranian married women residing in rural places. Glob J Health Sci. 2013;5(4):182-188. doi:10.5539/ gjhs.v5n4p182

30. Idris BI, Giskes K, Borrell C, et al. Higher smoking prevalence in urban compared to non-urban areas: time trends in six European countries. Health Place. 2007;13(3):702-712. doi:10.1016/j.healthplace.2006.11.001

31. Połtyn-Zaradna $\mathrm{K}$, Zatońska $\mathrm{K}$, Basiak $\mathrm{A}$, et al. Sociodemographic characteristic of changes in smoking patterns in rural and urban population of PURE Poland study: findings from 6-year follow up. BMC Public Health. 
2019;19(1):6. doi:10.1186/s12889-018-6354-0

32. Peer N, Bradshaw D, Laubscher R, Steyn N, Steyn K. Urban-rural and gender differences in tobacco and alcohol use, diet and physical activity among young black South Africans between 1998 and 2003. Glob Health Action. 2013;6:19216. doi:10.3402/gha.v6i0.19216

33. Jayamani V, Gopichandran V, Lee P, Alexander G, Christopher S, Prasad JH. Diet and physical activity among women in urban and rural areas in South India: a community based comparative survey. J Family Med Prim Care. 2013;2(4):334-338. doi:10.4103/2249-4863.123782

34. Muntner P, Gu D, Wildman RP, et al. Prevalence of physical activity among Chinese adults: results from the International Collaborative Study of Cardiovascular Disease in Asia. Am J Public Health. 2005;95(9):1631-1636. doi:10.2105/ajph.2004.044743

35. Mielgo-Ayuso J, Aparicio-Ugarriza R, Castillo A, et al. Physical activity patterns of the Spanish population are mostly determined by sex and age: findings in the ANIBES study. PLoS One. 2016;11(2):e0149969. doi:10.1371/ journal.pone.0149969

36. Drygas W, Kwaśniewska M, Kaleta D, et al. Epidemiology of physical inactivity in Poland: prevalence and determinants in a former communist country in socioeconomic transition. Public Health. 2009;123(9):592-597. doi:10.1016/j. puhe.2009.08.004

37. Reddy KS, Prabhakaran D, Shah P, Shah B. Differences in body mass index and waist: hip ratios in North Indian rural and urban populations. Obes Rev. 2002;3(3):197-202. doi:10.1046/j.1467-789x.2002.00075.x

38. Bakhshi E, Koohpayehzadeh J, Seifi B, et al. Obesity and related factors in Iran: the STEPS Survey, 2011. Iran Red Crescent Med J. 2015;17(6):e22479. doi:10.5812/ ircmj.17(6)2015.22479

39. Zou Y, Zhang R, Zhou B, et al. A comparison study on the prevalence of obesity and its associated factors among city, township and rural area adults in China. BMJ Open. 2015;5(7):e008417. doi:10.1136/bmjopen-2015-008417

40. Gao Y, Huang Y, Song F, et al. Urban-rural disparity of overweight/obesity distribution and its potential trend with breast cancer among Chinese women. Oncotarget. 2016;7(35):56608-56618. doi:10.18632/oncotarget.10968

41. Lerman-Garber I, Villa AR, Martinez CL, et al. The prevalence of obesity and its determinants in urban and rural aging Mexican populations. Obes Res. 1999;7(4):402406. doi:10.1002/j.1550-8528.1999.tb00424.x

42. Tydeman-Edwards R, Van Rooyen FC, Walsh CM. Obesity, undernutrition and the double burden of malnutrition in the urban and rural southern Free State, South Africa. Heliyon. 2018;4(12):e00983. doi:10.1016/j.heliyon.2018. e00983

43. Peytremann-Bridevaux I, Faeh D, Santos-Eggimann B. Prevalence of overweight and obesity in rural and urban settings of 10 European countries. Prev Med. 2007;44(5):442-446. doi:10.1016/j.ypmed.2006.11.011

44. Marques A, Peralta M, Naia A, Loureiro N, de Matos MG. Prevalence of adult overweight and obesity in 20 European countries, 2014. Eur J Public Health. 2018;28(2):295-300. doi:10.1093/eurpub/ckx143

45. Zhu D, Chung HF, Dobson AJ, et al. Age at natural menopause and risk of incident cardiovascular disease: a pooled analysis of individual patient data. Lancet Public Health. 2019;4(11):e553-e564. doi:10.1016/s24682667(19)30155-0

46. Svejme O, Ahlborg HG, Nilsson JA, Karlsson MK. Early menopause and risk of osteoporosis, fracture and mortality: a 34-year prospective observational study in 390 women. BJOG. 2012;119(7):810-816. doi:10.1111/j.14710528.2012.03324.x

47. Gilsanz P, Lee C, Corrada MM, Kawas CH, Quesenberry CP Jr, Whitmer RA. Reproductive period and risk of dementia in a diverse cohort of health care members. Neurology. 2019;92(17):e2005-e2014.

(C) 2020 The Author (s); This is an open-access article distributed under the terms of the Creative Commons Attribution License (http://creativecommons.org/licenses/by/4.0), which permits unrestricted use, distribution, and reproduction in any medium, provided the original work is properly cited. 